\title{
IMPACTO QUE GENERA EL DIAGNÓSTICO DE VIH EN MUJERES TRABAJADORAS DE LA REGIÓN DE ANTOFAGASTA Y METROPOLITANA.
}

\section{IMPACT OF HIV DIAGNOSIS IN WORKING WOMEN IN THE REGION OF ANTOFAGASTA AND THE METROPOLITAN REGION}

\author{
Natalia Leiva M. ${ }^{1}$, Jazmín Ortiz $Z^{2}{ }^{2}$, Valeska Robles $A .{ }^{3}$, Leonardo Vidal $\mathrm{H}^{4}$
}

\section{RESUMEN}

El propósito del presente artículo expone como el diagnóstico de VIH ha afectado a mujeres chilenas en su rol de trabajadoras, conociéndolo desde su propia perspectiva. Es una investigación cualitativa, donde se entrevistan a 3 mujeres sero positivo de edad entre los 20 y 65 años, que cuentan con experiencia laboral previo al diagnóstico de VIH. Los resultados identifican un antes y después del diagnóstico de $\mathrm{VIH}$, donde para mantener su rol de trabajadoras ocultan su diagnóstico al empleador y a sus compañeros de trabajo por miedo a ser discriminada; dan a conocer abiertamente su diagnóstico al contexto social que se desenvuelven para evitar prejuicios; o cambian su rubro laboral. De esta manera, se reconoce que la ley del SIDA de Chile no logra cubrir una protección real que permita el respeto, fiscalización y responsabilidad de estas normas, siendo vulnerados los derechos de las mujeres que viven con VIH. Las mujeres diagnosticadas sufren apartheid ocupacional e injusticia ocupacional, ya que no logran realizar su rol como trabajadoras debido a la desinformación que existe en la sociedad frente al VIH y a los estigmas que se encuentran en torno a ella, desencadenando prejuicios sociales históricos que han favorecido que mujeres vivan ocultando su realidad.

\section{Palabra clave:}

VIH - mujeres - trabajo - discriminación - terapia ocupacional - apartheid ocupacional.

\footnotetext{
${ }^{1}$ Terapeuta Ocupacional, Licenciada en Ciencias de la Ocupación Humana. Universidad Central de Chile. nileivam@gmail.com.

${ }^{2}$ Terapeuta Ocupacional, Licenciada en Ciencias de la Ocupación Humana. Universidad Central de Chile. jazmin.ivonne91@gmail.com.

${ }^{3}$ Terapeuta Ocupacional, Licenciada en Ciencias de la Ocupación Humana. Universidad Central de Chile. robles.valeska@gmail.com.

${ }^{4}$ Terapeuta Ocupacional, Licenciada en Ciencia de la Ocupación. Académico Universidad Central. Unidad de Gestión Clínica del Niño. Hospital Padre Hurtado. leonardo.vidal@ucentral.cl
} 


\begin{abstract}
The purpose of this article is to present how an HIV diagnosis has affected Chilean women in their role as workers, from the perspective of the women themselves. It is qualitative research involving three interviews which HIV-positive women between the ages of 20 and 65 who have work experience prior to receiving their HIV diagnosis. The results identify that there is a difference in the women's experience pre- and post-diagnosis, whereby to maintain their role as workers they hide their diagnosis from their employer and colleagues for fear of discrimination; that the women openly disclose their diagnosis in the social context in which they operate to avoid bias; or that they change their job. Thus, it is clear that the AIDS Chile legislation fails to offer real protection to ensure respect, execution of, and accountability regarding these rules being violated for women living with HIV. The diagnosed women suffer an occupational apartheid and occupational injustice, as they are unable to perform their role as workers due to the misunderstandings that exist in society regarding HIV and to the stigmas that surround it and, moreover, are victims of historical social biases that have favored women live hiding their HIV reality.
\end{abstract}

Key works: HIV - women - work - discrimination - occupational therapy - occupational apartheid. 


\section{INTRODUCCIÓN}

El Virus de Inmunodeficiencia Humana VIH es declarado por la Organización de Naciones Unidas (2004) como una de las pandemias más importantes y causante de millones de muertes alrededor del mundo. Ésta no sólo perjudica la salud de las personas, sino que también afecta todos sus ámbitos personales y sociales. Es por esto, que países y organizaciones se han movilizado a favor de políticas públicas que permitan la detección y prevención del VIH, además del acceso a un tratamiento adecuado e igualitario y a políticas públicas que eliminen la discriminación en personas que viven con VIH. Según Carlos Marx, el trabajo es una actividad vital para todo ser humano, permitiendo potenciar las habilidades de las personas y trasformar su condición de vida. (Zapata, 2011). Asimismo, la Asociación Americana de Terapia Ocupacional (2002) refiere que a través de las ocupaciones, como es el trabajo, permite generar independencia y autonomía en la persona promoviendo su inclusión en la sociedad. Por otra parte, ONUSIDA (2007) manifiesta que las mujeres diagnósticas con VIH enfrentan situaciones de discriminación en sus trabajos, siendo vulnerados sus derechos humanos y laborales.

\section{Contextualización de la investigación}

Según un estudio de caracterización de los factores de riesgo y vulnerabilidad de la población migrante frente al VIH/SIDA (Organización Internacional para las Migraciones, 2005) los casos diagnosticados están entre los 20 y 49 años principalmente, siendo ésta etapa de mayor productividad laboral en las personas. Asimismo, ONUSIDA indica que alrededor del $50 \%$ de las personas diagnosticadas con VIH son mujeres (2011), quienes han enfrentado situaciones de discriminación en sus trabajos por la existencia de prejuicios y estigmas sociales (2007). Asimismo, a nivel mundial existe desigualdad de género, donde mujeres experimentan discriminación y violencia, la cual se ve incrementada para aquellas que viven con VIH, predisponiendo la vulneración de sus Derechos Humanos. Por lo tanto, las mujeres se ven forzadas no sólo a luchar contra la desigualdad y vulnerabilidad de sus derechos, sino que además contra el estigma y la exclusión social que produce en la sociedad al ser sero positivo. (ONUSIDA, 2007)

Según lo señalado, ésta investigación cualitativa profundizará desde la perspectiva de mujeres que viven con VIH, cómo ésta patología ha afectado su desempeño ocupacional laboral y a limitado su participación en ocupaciones y roles significativos luego de ser diagnosticadas VIH positivo.

\section{Virus de la Inmunodeficiencia Humana (VIH)}

El VIH es aquel virus que altera o inhabilita la función del sistema inmunitario, dejando de proteger al cuerpo frente a infecciones y enfermedades. El Síndrome de Inmunodeficiencia Adquirida SIDA es un término que se aplica a los estadios más avanzados de la infección por VIH y se define 
por la presencia de alguna de las más de 20 infecciones oportunistas, aumentando la probabilidad de mortalidad en la persona (Organización Mundial de la Salud, 2004).

ONUSIDA estima que a nivel mundial existen 35,3 millones de personas viviendo con VIH (2013). Por su parte, el Ministerio de Salud de Chile (2012) señala que existe alrededor de 27 mil personas que viven con VIH/SIDA en Chile, existiendo un 9,6 por cien habitantes notificados con VIH y un 6,0 por mil habitantes de notificados de SIDA, de los cuales 23 mil de ellos podrían encontrarse viviendo con la enfermedad sin tener conocimiento de ello.

En Chile el diagnóstico del VIH se realiza a través del Test de Elisa en sistemas de salud públicos como privados. Según la ley del SIDA N 19.779 de Chile, señala que la realización de éste examen como del resultado es de carácter voluntario y confidencial. Además, esta ley protege de la discriminación ocurrida ante la realización del examen, donde existen diferentes sanciones y procedimientos a quienes falten a la ley según el Artículo $\mathrm{N}^{\circ} 4$ (Biblioteca del Congreso Nacional de Chile, 2011)

\section{Vulnerabilidad de la mujer}

ONU Mujeres (2013) manifiesta que las desigualdades entre el hombre y la mujer están muy arraigadas en las sociedades. Las mujeres en varios países no tienen acceso a un trabajo decente, ni a educación, ni a servicios de salud, entre otros. Cabe destacar que, Nina Ferenci expone que las mujeres son más propensas al contagio del VIH debido a una causa biológica que las predispone, ya que el VIH posee una carga viral mayor en el semen que en los fluidos vaginales, además que el tejido vaginal y del recto es mucho más vulnerable a la contracción de infecciones que el tejido que cubre el pene. De ésta manera, la vulnerabilidad de contraer el virus aumenta no sólo por causa biológica, sino que además por la desigualdad al acceso a la información del VIH, su prevención y a medidas que permitan el auto-cuidado sexual. Por lo tanto, las mujeres que viven con el VIH luchan contra el estigma y la exclusión social que se ven agravadas por la vulneración de sus derechos humanos. (British Broadcasting Corporation, 2004)

\section{Mujeres trabajadoras}

En Chile una gran proporción de los casos de personas con VIH están entre los 20 y 49 años, etapa de mayor productividad laboral (Organización Internacional para las Migraciones, 2005). Es por lo anterior, que la población más afectada se encuentra en la etapa de la adultez temprana ( 20 a 40 años) y parte de la adultez media (40 a 65 años), rangos etarios utilizados en ésta investigación. La adultez temprana es la etapa donde existe una estabilidad y crecimiento personal, es un período de culminación de sus objetivos y metas, comenzando a asumir roles en base al reconocimiento y demandas sociales, orientados a alcanzar mayores logros y desarrollando así su autonomía; mientras 
que en la adultez media es un ciclo vital que se destaca por ser un proceso de autoevaluación y balance, donde existe mayor exigencias laborales y de búsqueda de satisfacción y éxito en la vida profesional (Undurraga, 2011).

Carlos Marx (1844) manifiesta que "El trabajo es la actividad vital del ser humano a través de la cual transforma sus propias condiciones de vida y se transforma a sí mismo...

En él va desplegando todas sus potencialidades, perfeccionando habilidades, ingenio y creatividad". El trabajo es una actividad vital para el humano y permite que la persona transforme sus propias condiciones de vida personales y sociales (Zapata, 2011). El trabajo genera bienes y servicios que produce satisfacción para las necesidades individuales y de la comunidad en la que está inserto, siendo necesario para vivir, mantenerse, desarrollarse, satisfacer necesidades y ampliar el ámbito de relaciones sociales (Undurraga, 2011).

La Organización Internacional del Trabajo (2004) indica que cerca de 36,5 millones de personas que realiza algún tipo de actividad productiva en el mundo son seropositivas. La Organización Internacional para las Migraciones (2005) manifiesta que las personas que viven con VIH realizan principalmente trabajos independientes y ocasionales, de bajos ingresos, destacando que la mayoría de las mujeres diagnosticadas se desempeñan como dueñas de casa. Puesto que, la encuesta realizada por VIVO POSITIVO (2004), indica que el 20,1\% de los entrevistados realizaban trabajos de manera independiente, y de ellos el 70\% no contaban con un trabajo permanente, sino que eran ocasionales (Di Pillo, R. Ramírez, E., 2005).

Es fundamental destacar la Declaración Universal de Derechos Humanos proclamada por La Asamblea General de las Naciones Unidas en 1948, puesto que en ella se expresa la base de las leyes que se han incorporado en Chile. Por lo tanto, destacamos en el Artículo $\mathrm{N}^{\circ}$ 1: "Todos los seres humanos nacen libres e iguales en dignidad y derechos, y dotados como están de razón y conciencia, deben comportarse fraternalmente los unos con los otros"; en el Artículo $\mathrm{N}^{\circ}$ 23: "Toda persona tiene derecho al trabajo, a la libre elección de su trabajo, a condiciones equitativas y satisfactorias de trabajo y a la protección contra el desempleo" (Biblioteca del Congreso Nacional de Chile, 1948).

Por consiguiente, la ley del SIDA declara en el Artículo $\mathrm{N}^{\circ} 7$ que ningún sector laboral público o privado se podrá condicionar la contratación, permanencia o renovación del empleo, o de exigir el examen de VIH el cual es confidencial (Biblioteca del Congreso Nacional de Chile, 2005).

Cabe destacar que en Chile el año 2012, se aprueba la Ley 20.609 llamada Antidiscriminación o Ley Zamudio, que protege y respalda a cualquier persona que reciba una discriminación arbitraria, es decir, toda distinción, exclusión o restricción que no sea justificable, realizada por un agente del Estado o particulares, causando privación, perturbación o amenaza en el ejercicio legítimo de los derechos fundamentales establecidos por el país o en tratados internacionales sobre derechos humanos ratificados por Chile y que se encuentren vigentes. (Biblioteca del Congreso Nacional de Chile, 2012) 


\section{La perspectiva desde la terapia ocupacional}

La Organización Internacional del Trabajo (2004) refiere que el trabajo es un conjunto de actividades humanas remuneradas o no, que producen bienes o servicios en una economía, que satisfacen las necesidades de una comunidad o proveen los medios de sustento necesarios para los individuos.

Se efectuó una revisión bibliográfica exhaustiva desde la terapia ocupacional centrada en las personas con VIH/SIDA, orientada en el sexo femenino, la vulneración de sus derechos y su desempeño ocupacional laboral. No obstante pese a haber información ésta sólo se focalizaba en el diagnóstico, tratamiento e intervenciones principalmente biomédicas, careciendo de una perspectiva psicosocial y orientada en los derechos de las mujeres afectadas, como es el propósito central de ésta investigación.

Dentro de los conceptos de la terapia ocupacional se encuentra la subjetividad, entendida como el resultado de la relación del sujeto en todas sus áreas con los diferentes contextos familiares, ambientales, culturales, políticos, laborales, y sociales. La subjetividad se expresa a través de la praxis, con la finalidad de que la persona pueda dejar una huella social y en consecuencia, relacionarse con el quehacer de la persona, sus ocupaciones, actividades y acciones (Galheigo, 2007). Por su parte, Kronenberg y Pollard (2007) identifican el concepto de apartheid ocupacional, como las condiciones del entorno que niega el acceso a la participación de ocupaciones significativas y legítimas de las personas marginadas, siendo el resultado de limitaciones políticas irresponsables que se replican en esferas sociales, culturales y económicas, las cuales fomentan la desigualdad dejando en peligro la salud y bienestar de los individuos, comunidades y sociedades. Esta imposición perpetúa en la ignorancia y es posible que las personas no conozcan su potencial convencidas que no pueden cambiar el ambiente en el que viven. Por lo tanto, se obtiene una injusticia ocupacional donde la participación en la ocupación de la persona se margina, limita, segrega y se prohíbe de cualquier modo.

De esta manera, Ramugondo (2007) hace referencia que el vivir con un diagnóstico de VIH/SIDA supone un grave desafío para la persona. Sin embargo, lo que hace al VIH diferente son las controversias psicosociales que lo acompañan, donde su magnitud afecta más allá del individuo y su familia. Por ende, las condiciones de vida de las mujeres y la discriminación que enfrentan, son legados del estigma social ligado al VIH/SIDA. El derecho humano de poder desempeñar empleos que entreguen un sentido y determinen su calidad de vida, es frecuentemente negada por la sociedad como consecuencia de un legado discriminador histórico. El apartheid e injusticia ocupacional se potencia cuando los recursos o el desarrollo de ocupaciones y roles significativos están reservado 
sólo para algunos, mientras que para otros se les ha negado sin poder elegir por ellos mismos y siendo juzgados por ser diferentes, convirtiéndolos en menos merecedores de sus derechos.

La Asociación Americana de Terapia Ocupacional (2002) menciona que "Todas las personas necesitan ser capaces o capacitarse para comprometerse en ocupaciones de su necesidad y elección, para crecer a través de lo que ellos hacen, y experimentan independencia e interdependencia, igualdad, participación, seguridad, salud y bienestar". Por lo tanto, las mujeres viviendo con VIH al no cumplir con su rol de trabajadoras carecen de las características mencionadas por los autores citados.

\section{Fundaciones en apoyo de las personas que viven con VIH.}

En Chile existen varias fundaciones $\mathrm{u}$ organizaciones que apoyan a las personas que viven con VIH, desde el apoyo con los medicamentos, entrega de información o en el empoderamiento de sus derechos. Durante la investigación se realizó contacto con la Fundación Savia, que es una organización social sin fines de lucro, cuyo interés fundamental es cooperar con las personas que viven con VIH/SIDA, con la finalidad de romper las barreras de la incomprensión, la exclusión social, la intolerancia y la discriminación que se ejerce contra quienes sufren esta situación. Por otra parte, las entrevistadas son parte de la ICW Chile y Agrupación Regional de Personas Viviendo con el VIH/SIDA (ARPEVIH), donde ICW Chile es organización comunitaria reconocida internacionalmente, sin fines de lucro liderada por mujeres viviendo con VIH/SIDA, que defiende el reconocimiento y el ejercicio de los derechos de las mujeres, adolescentes y niñas/os chilena/os viviendo con VIH-SIDA. Por su parte, ARPEVIH es una organización de la región de Antofagasta, que inició en 1998 con la finalidad de crear espacios de encuentro, apoyo y conversación entre personas que viven con VIH/SIDA, para luego cooperar con los medicamentos de alto costo para la época. Actualmente están enfocados a promover el desarrollo íntegro de las personas que viven con VIH/SIDA y sensibilizar a la comunidad para prevenir la propagación del virus.

\section{METODOLOGÍA}

Esta investigación se basó en el modelo cualitativo naturalista debido a que se entendió la realidad por medio de los valores y los conocimientos que se construyen en la cotidianidad de las mujeres que viven con VIH, permitiendo la validación de su diversidad las cuales les da sentido a sus experiencias (Hernández, Fernández, \& Baptista, 2006).

A su vez, desde el diseño fenomenológico las investigadoras fueron consideradas parte de la situación analizada, por lo que sus experiencias e ideologías inciden en el estudio, sin que estas sean condicionadas por las teorizaciones efectuadas en la investigación (Briones, 2002).

Desde la Terapia Ocupacional se avaló este estudio desde el paradigma social de la ocupación, el cual describe a la ocupación como fenómeno social y político enfocado en la justicia social y los derechos humanos de las personas. De esta manera, permitió fomentar la emancipación y el 
empoderamiento, comprendiendo el sistema a un nivel macro y como éste influyó en la perspectiva que tienen las personas sobre sus ocupaciones dentro del sistema.

La investigación se realizó a mujeres dentro del ciclo vital de la adultez temprana y media, debido a que en esta etapa el trabajo cumple un gran significado y sentido de identidad, considerando que la discriminación $\mathrm{y}$ desigualdad laboral que han enfrentado las mujeres se ha perpetuado históricamente. Por lo tanto, la investigación analizó sus experiencias en base a la vulneración de sus derechos por ser mujer y vivir con VIH dentro de su rol como trabajadoras.

El estudio se centra en mujeres viviendo con VIH entre los 20 y 65 años, con experiencias laborales previas y residentes en Chile. El tamaño de la muestra fue de 3 mujeres diagnosticadas de VIH contactadas por Fundación Savia ${ }^{5}$ y que son de la región de Antofagasta y región Metropolitana, debido a que sólo ellas accedieron a ser entrevistadas y cumplían con los criterios solicitados.

Los criterios de inclusión y exclusión utilizados son:

- Mujeres

- $\quad$ Entre los 20 y 65 años

- Nacionalidad chilena

- $\quad$ Sero positivo

- Experiencia laboral.

Para reunir la informaciónn se utilizó una Entrevista semi-estructurada aplicada de manera individual a cada participante en solo una sesión de dos horas cronológicas. Asimismo, su elaboración con formato semi-estructurado procuró dar libertad a las entrevistadas de expresar sus experiencias e indagar con mayor profundidad en los temas de interés para la investigación. La entrevista se clasificó en 11 ítems que abordaron diferentes aspectos de las participantes, como se podrá observar en la descripción de cada ítem de la Tabla 1.

La Pauta de Entrevista se construyó en base al Marco de Trabajo para la práctica de Terapia Ocupacional (2002) específicamente el perfil ocupacional, las áreas de ocupación, los patrones del desempeño y el contexto; la Ley del SIDA N¹9.779 (2005); y los capítulos VI, VII, XXIII del libro Terapia Ocupacional sin Fronteras.

Para proteger la integridad de las mujeres y evitar la vulneración de su dignidad, se elaboró el instrumento con la colaboración de la terapeuta ocupacional Luz María Yaconi, experta en la temática y directora ejecutiva de la Fundación Savia.

Las entrevistas fueron grabadas y consecutivamente transcritas para garantizar la confiabilidad de los datos recolectados.

Posteriormente, se obtuvo diferentes categorías codificando la información por medio de la identificación de unidades de significado, categorización y asignación de códigos. La categorización

\footnotetext{
5 Fundación Savia es una organización social sin fines de lucro, independiente y cuyo interés fundamental es cooperar con las personas que viven con VIH/SIDA. Dirección: Tegualda \#1832 Ñuñoa, Santiago, Chile. Teléfonos: (56) 0222690937 Fax: 22252714. Correo electrónico: savia@fundacionsavia.cl

8
} 
se realizó según los ítems de la entrevista y luego se asignaron los códigos según los ejes importantes y relevantes manifestados durante la entrevista en cada uno de sus ítems. Cada una fue analizada y comparadas entre sí, formando nuevas categorías y/o agrupándolos con otras, reiterando el proceso de "comparación constante" entregando un código a cada categoría (Hernández, Fernández, \& Baptista, 2006). La codificación fue utilizada con el propósito de revelar significados potenciales, categorías y/o respuestas de mayor representatividad. De esta manera, se clasifican y describen las preguntas realizadas a las entrevistadas según la Tabla 1.

Finalmente, se triangularon los datos comparando las diferentes fuentes abordándolas de distintas perspectivas para enriquecer así el análisis de la información.

\begin{tabular}{|c|c|c|}
\hline \multicolumn{3}{|r|}{ Tabla 1. Categoría de Análisis } \\
\hline & $\begin{array}{l}\text { Clasificación de } \\
\text { preguntas }\end{array}$ & Descripción \\
\hline 1. & Antecedentes personales & Nombre. Edad. \\
\hline 2. & Antecedentes laborales & Trabajos anterior y actual. \\
\hline 3. & $\begin{array}{l}\text { Discriminación por ser } \\
\text { Mujer }\end{array}$ & Lo experimentan. \\
\hline 4. & $\begin{array}{l}\text { Rol de mujeres } \\
\text { trabajadoras }\end{array}$ & $\begin{array}{c}\text { Relevancia del rol y su significado. Trabajadoras y/o jefas de } \\
\text { hogar. Diferencias laborales por ser mujeres. }\end{array}$ \\
\hline 5. & Diagnóstico de VIH & Experiencia ante el diagnóstico. Modo de enfrentar. \\
\hline 6. & Servicios de salud & $\begin{array}{l}\text { Seguro social y de salud suficientes. Dificultades para asistir a } \\
\text { controles médicos }\end{array}$ \\
\hline 7. & $\begin{array}{l}\text { Trabajo al momento del } \\
\text { diagnóstico }\end{array}$ & $\begin{array}{l}\text { Labor del momento. Comunicar diagnóstico en contexto } \\
\text { laboral. Alteración de rutina. }\end{array}$ \\
\hline 8. & $\begin{array}{l}\text { Opinión crítica social de } \\
\text { las entrevistadas }\end{array}$ & $\begin{array}{c}\text { Opinión sobre los Derechos Humanos, ley del SIDA y Test de } \\
\text { Elisa. }\end{array}$ \\
\hline 9. & Mujeres viviendo con VIH & Realidad en Chile. Deberes. \\
\hline 10. & $\begin{array}{l}\text { Participación en } \\
\text { organización social }\end{array}$ & Participación activa. Percibe un cambio. \\
\hline 11. & En la actualidad & Reflexiones de las entrevistadas. \\
\hline
\end{tabular}

Fuente: Elaboración particular de clasificación de preguntas realizadas con descripción, para favorecer la comprensión de la información. 


\section{CONSIDERACIONES ÉTICAS}

Se realizó una invitación a través de la Fundación Savia y de la terapeuta ocupacional Luz María Yaconi, a mujeres viviendo con VIH para colaborar y ser voluntarias de éste estudio, convocando a quienes participaban en organizaciones relacionadas con el apoyo de personas que viven con VIH/SIDA. Luego, se desarrolló una reunión individual con el propósito de explicar el objetivo de la investigación, las características principales de las temáticas abordadas y el resguardo de su anonimato, especificando que la investigación evitaría transgredir o causar daño, perjuicios o afecciones. Por otra parte, cada una de las opiniones, puntos de vista, elecciones, valores y/o creencias personales entregadas u expresadas por las mujeres viviendo con VIH fueron plenamente respetados.

Posterior a la aprobación de su participación, se solicitó la lectura y firma del consentimiento informado, el cual expresa la confidencialidad de datos personales e información entregada, la cual será grabada y usada sólo con fines propios de la investigación.

\section{RESULTADOS}

Para respetar la confidencialidad y anonimato de las participantes, se recurre a clasificar las entrevistas individuales en: M1, M2 y M3.

Con el propósito de facilitar la exposición de los resultados, estos serán presentados en apartados según la Clasificación de Preguntas señaladas en la Tabla 1.

\section{Antecedentes Personales}

M1 tiene 54 años, es soltera, sin hijos, vive en la región Metropolitana con sus padres y estudió técnico en turismo, sin embargo no encontró trabajo en el área de estudio.

Por su parte, M2 tiene 59 años, es soltera sin hijos, vive en la región de Antofagasta con su padre, y estudió Técnico en secretaría.

Finalmente, M3 está casada sin hijos, vive la región de Antofagasta con su esposo, y estudió hasta segundo de enseñanza media, y se desarrolla como secretaria en una Empresa de Transportes.

\section{Antecedentes Laborales}

En el ámbito laboral M1 se desempeña hace 17 años como vendedora, por su parte M2 ha trabajado como ejecutiva de ventas, secretaria y actualmente desempeña un cargo administrativo en una organización social, mientras que M3 fue trabajadora sexual y tras recibir su diagnóstico creó una empresa con su marido, desempeñándose como secretaria. 


\section{Discriminación por ser mujer}

Todas las participantes concuerdan en que no han experimentado discriminación ni vulnerabilidad de sus derechos por ser mujeres, expresando que se han validado y empoderado de sus derechos.

Destacamos a M1 que refiere: "Las cosas que yo he hecho, como que yo me he parado aquí, yo he mostrado que sé trabajar y que no me han discriminado pa' nah el ser mujer, o sea a lo mejor yo me he hecho valer como mujer, y yo necesito éste sueldo y estas cosas". Por su parte, M3 destaca: "Para nada, en mi trabajo tengo a cargo a 35 personas con mi esposo y la verdad que he tenido mucho apoyo de hecho ellos, saben lo de mi enfermedad y jamás han cambiado el trato".

Sin embargo, destacan que si han recibido discriminación por su condición de VIH. De ésta manera, M2 manifiesta: "Yo fui discriminada en algún momento por una jefa que yo tuve hace muchos años, que era la Directora. Yo informé y dije a mi jefa sobre mi condición de VIH y ella no quería que se lo dijera a nadie, y era decisión mía y fue por eso que yo lo hice público. Fue bastante grave, ella fue muy agresiva, me trato muy mal en ese momento". No obstante refiere que el hecho de haber estado empoderada de sus derechos la llevó a no ser despedida y que con el tiempo disminuyera la discriminación.

M3 destaca finalmente: "El año 2010 cuando me rehabilité de las drogas y me junte con mi esposo, él me dijo que viajara a Santiago a reencontrarme con mi familia. Fui a la casa de una tía y lo primero que hicieron fue poner cloro por toda la casa, separarme mis utensilios y lavarlos en agua caliente".

\section{Rol de mujeres trabajadoras}

El rol de trabajadoras presenta gran relevancia en las entrevistadas, manifestando que les permite tener la libertad de elegir y promover su crecimiento personal.

En el caso de M1 y M2 ambas son trabajadoras y jefas de hogar, mientras que M3 comparte tal rol con su esposo.

M1 expresa “...siempre he estado entorno a iyo trabajar!, a iyo esto! y jesto otro ;... o sea iyo manejo!, o sea, yo soy como el hombre de la casa”.

M2 manifiesta "Es súper importante porque una es independiente, uno hace con su vida lo que estima necesario, y tiene la libertad de elegir y de hacer, entonces ser jefa de hogar uno administra como mejor le parece y conviene, y esto es un aporte a la sociedad".

M3 refiere "El trabajar y ser un aporte en el hogar es el reflejo del trabajo en conjunto del matrimonio y la lucha por los objetivos creados por el mismo”.

Respecto a su percepción sobre las diferencias por ser mujeres en el área laboral, las tres coinciden enfatizando que gracias a su impronta han dado a conocer sus diversas habilidades.

M1 enfatiza "No me han discriminado pa' nah el ser mujer, o sea a lo mejor yo me he hecho valer como mujer".

M2 señala “...en lo laboral por supuesto que no, porque yo trabajo en un servicio que protege a la mujer”. 
M3 declara "Para mi aunque parezca extraño es importante el trabajo para mi crecimiento personal pero no es lo fundamental".

\section{Diagnóstico de VIH}

M1 hace 14 años ingreso de urgencias a la UCI siendo diagnosticada de VIH. Su percepción del diagnóstico fue inmediatamente asociado a muerte. No obstante, expresa su ímpetu por buscar soluciones y enfrentarlo, manifestando que "llevo un dolor súper pesado, y es una carga que se lleva constantemente" pero que sólo su entorno cercano conoce, debido al miedo de ser discriminada.

Hace 16 años M2 conoce sorpresivamente su diagnóstico, debido a que su pareja fallece luego de ser internado de urgencias por presentar la fase final del SIDA. Confrontar su reciente viudez y diagnóstico la llevó a comunicarlo con su entorno. "tengo que seguir viviendo no más, es una enfermedad crónica que tengo".

M3 conoció su diagnóstico hace 5 años cuando vivía en situación de calle y abusaba de sustancias. Manifiesta impotencia frente a su contagió "sali del hospital y sólo lloré, no sabía qué hacer pensaba que era sinónimo de muerte", puesto que fue su ex pareja y no producto de su desempeño laboral. Con el tiempo conoció a su actual esposo, quien la impulso a dejar la prostitución y la drogadicción. M3 refiere estar en un período en el que ha descubierto sus capacidades y que pretende formar un hogar y familia.

Por otra parte, el Test de Elisa que refiere confidencialidad en su diagnóstico, las entrevistadas enfatizan que existen situaciones de discriminación por los mismos profesionales de la salud. Como fue el caso de M3, quien menciona haberse sentido discriminada por paramédicos y enfermeros, argumentando que es efecto de la ignorancia frente al VIH en nuestra sociedad.

\section{Servicios de Salud}

Todas las entrevistadas son atendidas por el servicio público (FONASA), pero estos no son suficientes para cubrir los gastos totales de sus medicamentos, debiendo recurrir a otras alternativas.

En cuanto a la posibilidad para asistir a controles médicos con permiso de sus trabajos, sólo M1 debía ocultar el propósito de sus permisos debido a que desconocían su diagnóstico. Por su parte M3 dejó los fármacos, refiriendo que le desencadenaba efectos negativos después de consumirlos.

\section{Trabajo al momento del diagnóstico}


Al momento del diagnóstico M1 se desempeñaba al igual que en la actualidad de vendedora, debido al temor de ser discriminada oculta su diagnóstico "en ventas siempre hay como una rivalidad, imagínate que supieran que yo tengo problemas de salud”.

Por otra parte, para asistir a controles médicos y retirar sus medicamentos siempre se debe organizar "siempre me planificó...todo en mis días libres, nunca en mis horarios de trabajo". Asimismo manifiesta que es difícil coordinar sus tiempos puesto que "...no hay permiso, o sea yo estoy en una empresa no estoy en una parte que sea de beneficencia. Asi de duro”.

M2 era secretaria, menciona que "estaba trabajando bien, pero de un momento a otro el mundo se me desmorono... comencé a tener problemas con mi jefa, y problemas graves de agresión” por lo que decidió acudir a las autoridades y reportar la situación, desde ese momento fue "cuando ella (jefa) cambio su actitud conmigo... y cambio bastante y ahí después yo pude trabajar tranquila".

Señala no presentar problemas para asistir a controles médicos o retirar sus medicamentos actualmente, aunque confiesa que ella hace 10 años atrás compraba "por el mercado negro los medicamentos, para mí y para otras personas que lo necesitaran" y estos "me salían 340 mil pesos la terapia”.

M3 refiere que ella "vivía en la calle, consumía drogas y ejercía el comercio sexual" comenta que su labor en aquel entonces sólo lo ejercía para abastecer su adicción, de hecho expresa que "no era algo que yo hubiese deseado, fueron las circunstancias las que me llevaron a eso". Posterior a su rehabilitación, trabaja como secretaria administrativa en "una empresa que creamos con mi esposo".

Por otra parte, menciona que hace años atrás inicio "con tratamiento (para el VIH, pero éste) me afecto mucho ya que me sentía muy mal, la verdad es que debido a eso es que deje la terapia”.

\section{Opinión crítica social de las entrevistadas.}

Referente al planteamiento de los derechos humanos "ser libres e iguales a los demás" las entrevistadas concuerdan que no son respetados, más aún en las personas que viven con VIH, producto de la desinformación y el prejuicio ante la forma de contagio.

Respecto a la ley del SIDA las entrevistadas señalan que no es efectiva en su totalidad, debido a que han presenciado discriminación en contextos laborales y de salud. Asimismo, el Test de Elisa que refiere confidencialidad en su diagnóstico, las entrevistadas enfatizan que existen situaciones de discriminación por los mismos profesionales de la salud. Como fue el caso de M3, quien menciona haberse sentido discriminada por paramédicos y enfermeros, argumentando que es efecto de la ignorancia frente al VIH en nuestra sociedad. 


\section{Mujeres viviendo con VIH}

La realidad de las mujeres que viven con VIH en Chile, de acuerdo a lo comentado por las entrevistadas, indican que las mujeres viven ocultas su diagnóstico por miedo a diferencia de los hombres. Más aún enfatizan que las campañas publicitarias gubernamentales entregan información errónea, como mencionan M1 y M2 los medios promueven como método de prevención la pareja única siendo que ellas fueron contagiadas por sus parejas "únicas".

Ante la pregunta sobre los deberes que tienen las mujeres que viven con VIH, todas concluyeron que debe existir un empoderamiento por el autocuidado, así como colaborar en facilitar los testimonios sobre su realidad.

\section{Participación en organización social}

Todas las entrevistadas participan de un organismo social, con propósitos de confidencialidad mencionaremos conjuntamente todas las organizaciones de las cuales nuestras participantes tienen un rol activo, siendo estas: Fundación Savia, Agrupación de personas viviendo con VIH, familiares y amigos (ARPEVIH) y Comunidad Internacional de mujeres viviendo con VIH y SIDA Chile (ICW Chile). Las entrevistadas concuerdan que se acercaron a éstas organizaciones una vez diagnosticadas, para buscar apoyo e información entorno al VIH. M1 apoya ocasionalmente en diferentes actividades para reunir fondos o propias de la organización. Por su parte, M2 Y M3 cumplen un rol activo dentro de su organización, realizando charlas relatando su historia de vida e entregando información a la comunidad. Las entrevistadas que se genera un cambio social en estos organismos debido a que difunden información y empoderan a las personas con $\mathrm{VIH}$ en sus derechos y deberes como a la sociedad. Cabe destacar que una de las entrevistadas, que por resguardo a la confidencialidad no mencionaremos, es una de las fundadoras de una de las organizaciones mencionadas, donde destaca: "El objetivo al comienzo era conversar con las personas, la idea era hablar con nuestro pares. De ahí comenzamos a darnos cuenta que estaba la problemática de los medicamentos, que no se podían conseguir medicamentos, después teníamos dos objetivos. Después te das cuenta que están siendo vulnerados los derechos, en el hospital, en la escuela, que se yo, de ahi teníamos tres objetivos. Así fuimos creciendo, de cuales eran nuestras necesidades. Luego armado legalmente, por una personalidad jurídica, y todo eso hacerlo. Y así, hemos ido creciendo en el tiempo por estos 15 años."

\section{En la actualidad}

M1 confiesa que ha sido una gran carga y dolor vivir con VIH, por lo que determina que no ha sido fácil. Sin embargo, expresa que "vivir con VIH (la ha hecho ser) más humana todavía... crecer más como persona”. Asimismo, concluye lo importante y orgullosa que se siente al ser mujer. 
M2 refiere que aún existe discriminación de ciertos compañeros laborales hacia su situación de salud. No obstante, pretende al jubilar dedicar su tiempo mayormente a su organización social y también una empresa familiar. Finalmente expresa una gran dificultad al vivir con VIH "Ser una mujer es dificil. Pero también (significa) fuerza y valentía".

M3 indica que se proyecta trabajando en su empresa, "vivir el día a día" y concluye manifestando que ser mujer viviendo con VIH ha significado "revivir".

\section{DISCUSIÓN}

Al analizar los resultados se logra determinar que existen cambios tras el diagnóstico de VIH en mujeres que cumplen su rol como trabajadoras. Aunque las opiniones y percepciones de ellas son contrapuestas, hay un marcado antes y después del diagnóstico de VIH produciendo cambios significativos en sus relaciones sociales con familiares y compañeros de trabajo, modificación en los hábitos, reestructuración de rutinas, cambios relevantes en el área del desempeño ocupacional del trabajo, roles laborales y los distintos contextos donde su realidad debe ser alterada desencadenando mecanismos para sobrellevar este nuevo estilo de vida.

Cabe señalar que durante la construcción de la investigación como de la entrevista, no se consideró abarcar y conocer otras áreas del desempeño ocupacional debido a que el foco se centró en sólo indagar la perspectiva del área laboral de las entrevistadas. Asimismo, no se incluyeron preguntas en base a su forma de contagio, si estaban en tratamiento o en qué estadio de VIH/SIDA estaban viviendo, ya que no se consideraban relevantes para los propósitos de ésta investigación. Destacamos que hablar de VIH/SIDA desde la realidad de la persona es completamente difícil, puesto que existe una discriminación social histórica que hace que las mujeres vivan ocultando su realidad. Por lo tanto, al realizar las entrevistas se evitó indagar en temas que no eran trascendentes y no cumplían con el objetivo de la investigación, ya que previamente a ellas se les comunicaba que la idea era conocer su realidad en base al área laboral. Por consiguiente, las autores consideran que son aspectos relevantes por explorar en futuras investigaciones desde la terapia ocupacional.

Si bien la ley del SIDA de Chile indica protección para las personas que viven con VIH (Biblioteca del Congreso Nacional de Chile, 2005), las entrevistadas manifiestan un sentimiento de vulnerabilidad frente a sus derechos por lo que deben silenciar su verdad para no ser despedidas o discriminadas, ya que han observado y experimentado desprotección en servicios de salud y sistemas laborales. Cabe destacar, que las entrevistadas reconocen que al estar empoderadas de sus derechos, son capaces de buscar apoyo y de sobrellevar este nuevo estilo de vida. Sin embargo, reconocen que existen varias mujeres que viven con VIH/SIDA y que están escondidas por temor a la discriminación y a la vulneración de sus derechos.

En relación al significado que las entrevistadas dan frente el trabajo, refieren que es una actividad de interés que permite la satisfacción de sus necesidades, desarrollo de sus habilidades, crecimiento personal y sentimiento de libertad, así se confirma lo indicado por Carlos Marx (Zapata, 2011). No obstante, tras el diagnóstico de VIH positivo las entrevistadas sufren discriminación laboral con intención de despido, cambios a trabajos independientes o deben vivir ocultado su 
realidad en el contexto laboral debido al temor de ser despedidas, quedando demostrado el estudio de la Organización Internacional para las Migraciones (2005) donde indica que las personas que viven con VIH se desempeñan en trabajos independiente u ocasionales.

Ramugondo (2007) manifiesta que vivir con VIH/SIDA supone un grave desafío para la persona, debido al legado histórico de prejuicio ante el VIH, donde en la investigación queda evidenciado cuando las entrevistadas manifiestan la discriminación que sufrieron en servicios de salud y en sus trabajos, que se debe principalmente a los prejuicios que existen por las vías de contagio como también la ignorancia respecto al tema.

Los autores Kronenberg, Salvador, \& Pollard (2007) reconocen el apartheid ocupacional como las condiciones del entorno que obstaculiza el acceso a la participación de sus ocupaciones significativas, tras limitaciones políticas deficientes que impulsan la desigualdad social dejando en peligro el bienestar de las personas. Esto queda demostrado en las mujeres entrevistadas donde ven amenazada su participación de sus ocupaciones sólo por el hecho de vivir con VIH, vulnerándose sus derechos humanos. Sin embargo, se observa que las entrevistadas se encuentran empoderadas frente a sus derechos y al VIH, por ende son capaces de enfrentar su realidad y de respetar sus derechos en sus contextos personales. En consecuencia, el entorno que ellas se desenvuelven se encuentra informado sobre la realidad del VIH, eliminando prejuicios personales y el miedo a la muerte que el $\mathrm{VIH} / \mathrm{SIDA}$ conlleva.

Ramugondo (2007) menciona lo amenazante y agobiante que resulta para las mujeres viviendo con VIH enfrentar la sociedad. Si bien en este estudio se presencia como las entrevistadas contrarrestaron estas dificultades y han podido enfrentan la adversidad, a las autoras le cabe cuestionarse que estos casos son dignos de respeto y ejemplos de superación. No obstante, se debate la presencia de mujeres que viven ocultando su diagnóstico como es la situación en una de las mujeres entrevistadas, que temen manifestar su real situación de salud, por el hecho de cómo mencionan los autores anteriormente, ser estigmatizadas y excluidas socialmente.

Se destaca la apreciación de las entrevistadas referente a la desinformación y la tergiversada asociación entre el VIH/SIDA como sinónimo de muerte, afectando la perspectiva social frente al tema. De esta manera, se realizó una crítica a las estrategias que usa la sociedad o el Estado frente a esta realidad, la cual carece de información clara y fundamentada sobre la real prevención del VIH, como es el caso de las campañas que estipulan tener una pareja única como método de prevención, siendo que ésta es contrario a las mujeres entrevistadas, en el que se observó que sus parejas estables fueron causales de su diagnóstico.

Finalmente, el rol de terapeuta ocupacional en pro de las mujeres que viven con VIH, es la entrega de herramientas que permitan el empoderamiento de sus derechos, de tal forma, que se pueda 
eliminar el apartheid ocupacional que afecta su desempeño en ocupaciones significativas. Asimismo, puede ser una guía en la reestructuración de sus hábitos y rutinas, permitiendo un mayor autocuidado y participación social, como además del cumplimiento de los roles que posee una mujer trabajadora, considerando su motivación intrínseca. Por consiguiente, los terapeutas ocupacionales debemos ser agentes de cambio por medio del empoderamiento de los derechos humanos en las personas que viven con VIH/SIDA, de esta manera favorecemos la eliminación del apartheid ocupacional y potenciaremos su resiliencia para promover su desempeño ocupacional en actividades significativas, como es el ámbito laboral, permitiendo su efectiva inclusión social. Por lo tanto, se invita a colegas y profesionales de la salud y social, a conocer la realidad de las personas que viven con VIH/SIDA, a sensibilizar a la comunidad, contribuir en organizaciones que colaboran con sus derechos, ampliar los estudios autónomos referente a las problemáticas de las personas afectadas, realizar y publicar investigaciones y experiencias en ésta realidad, para así empoderar a la comunidad y promover políticas públicas que generen cambios en la sociedad. De esta manera disminuir los prejuicios y estigmas que rodean ésta problemática, fomentando así la justicia ocupacional, permitiendo que las personas diagnosticadas con VIH/SIDA logren desenvolverse en sus ocupaciones significativas y en la sociedad de manera autónoma e independiente, sin ocultar su realidad y sin que sus derechos sean vulnerados.

\section{AGRADECIMIENTOS}

Expresamos nuestro agradecimiento a Fundación Savia quienes nos acogieron y sumergieron en la realidad chilena de las personas que viven VIH. Esta es una organización social sin fines de lucro e independiente de tendencias políticas o religiosas, que contribuye diariamente con empatía y perseverancia por las personas que viven con VIH, quebrantando las barreras de la injusticia, exclusión y discriminación social.

Por otra parte, quisiéramos agradecer a los terapeutas ocupacionales Luz María Yaconi y Leonardo Vidal quienes nos orientaron y empoderaron de la realidad del VIH desde la perspectiva de la terapia ocupacional, obteniendo mejores logros en la investigación.

Finalmente, agradecemos a las tres mujeres entrevistadas por la posibilidad y privilegio de escuchar y conocer sus historias, que si bien fueron desgarradoras también nos entregaron ejemplos de vida e inspiración para salir adelante pese a toda adversidad. 


\section{REFERENCIAS BIBLIOGRÁFICAS}

- Asociación Americana de Terapia Ocupacional, AOTA. (2002). Marco de Trabajo para la Práctica de la Terapia Ocupacional: dominio y proceso. Santiago. Universidad de Chile. Comité de Ciencia de la Ocupación.

- Biblioteca del Congreso Nacional de Chile, BCN. (1948). Declaración Universal de los Derechos Humanos. Recuperado el 18 de mayo del 2013, en http://www.bcn.cl/ecivica/docs/declaracion.pdf

- Biblioteca del Congreso Nacional de Chile, BCN. (1990). Ley Fácil. Ley del SIDA. $\begin{array}{lllllll}\text { Recuperado el } & 16 \text { de } & \text { mayo }\end{array}$ http://www.bcn.cl/leyfacil/recurso?item_id=4226\&leng=es

- Biblioteca del Congreso Nacional de Chile, BCN. (2005). Ley $\mathrm{N}^{\circ}$ 19.779. Establece normas relativas al Virus de Inmunodeficiencia Humana y crea bonificación fiscal para enfermedades catastróficas. Recuperado el 16 de mayo del 2013, en http://www.leychile.cl/Navegar?idNorma=192511 
- Biblioteca del Congreso Nacional de Chile, BCN. (2012). Ley $\mathrm{N}^{\circ}$ 20.609. Establece medidas contra la discriminación. Recuperado el 15 de octubre del 2015, en http://www.ben.cl/leyfacil/recurso/ley-de-no-discriminacion

- Briones, G. (2002). Epistemología de las ciencias sociales. Bogotá: ARFO Editores e Impresiones Ltda.

- British Broadcasting Corporation, BBC (2004) Mundo. Que hace a la mujer más vulnerable?. $\begin{array}{lllllll}\text { Recuperado el } & 15 & \text { de } & \text { octubre } & \text { del } & \text { 2015, }\end{array}$ http://news.bbc.co.uk/hi/spanish/science/newsid_4035000/4035373.stm\#xq1

- Di Pillo, R. Ramírez, E. (2006). Tesis “El Sida y la relación laboral”. Páginas 32-36. Universidad de Chile, Facultad de Derecho. Santiago, Chile.

- Hernández, R., Fernández, C., \& Baptista, M. d. (2006). Metodología de la investigación. México: McGraw-Hill Interamericana de México S.A.

- Kronenberg, K., Simó, S., Pollard N. (2007). Terapia Ocupacional sin fronteras. Galheigo S. (ed), Terapia Ocupacional en el ámbito social, Capitulo 7. Editorial Médica Panamericana.

- Kronenberg, K., Simó, S., Pollard N. (2007). Terapia Ocupacional sin fronteras. (ed), Superar el Apartheit Ocupacional: Exploración preliminar de la naturaleza política de la Terapia Ocupacional. Liberar la espiritualidad: el juego como ocupación de la promoción de la salud en contexto de VIH/SIDA, Capitulo 6. Editorial Médica Panamericana. 
- Kronenberg, K., Simó, S., Pollard N. (2007). Terapia Ocupacional sin fronteras. (ed), Liberar la espiritualidad: el juego como ocupación de la promoción de la salud en contexto de VIH/SIDA, Capitulo 23. Editorial Médica Panamericana.

- Marx, C., (1844). Manuscritos Económicos y filosóficos. Antítesis del capital y el trabajo. Propiedad privada y capital. Recuperado el 20 de octubre del 2015, en https://www.marxists.org/espanol/m-e/1840s/manuscritos/man2.htm

- Ministerio de Salud de Chile, MINSAL. (2012). Departamento de Epidemiología. Informe Nacional "Evolución VIH SIDA, Chile 1984 - 2011". Recuperado el 17 de mayo del 2013, en http://epi.minsal.cl/epi/html/bolets/reportes/VIH-SIDA/InformePais_1984-2011_vih_sida.pdf

- Organización de Naciones Unidas Mujeres, ONU MUJERES (2013). Hechos y cifras: el VIH y el SIDA. Recuperado el 13 de mayo del 2013, de http://www.unwomen.org/es/what-wedo/hiv-and-aids/facts-and-figures

- Organización de Naciones Unidas SIDA, ONUSIDA (2007). Reducir el estigma y la discriminación por el VIH: una parte fundamental de los programas nacionales de sida. $\begin{array}{lllllll}\text { Recuperado el } & 18 \text { de }\end{array}$ http://data.unaids.org/pub/Report/2009/jc1521_stigmatisation_es.pdf

- Organización de Naciones Unidas SIDA, ONUSIDA (2011). Cómo llegar a cero: Más rápido. Más inteligente. Mejor. Recuperado el 18 de mayo del 2013, en 
http://www.unaids.org/sites/default/files/en/media/unaids/contentassets/documents/unaidspub lication/2011/JC2216_WorldAIDSday_report_2011_es.pdf

- Organización de Naciones Unidas SIDA, ONUSIDA (2013). Hoja informativa mundial 2013. $\begin{array}{lllllll}\text { Recuperado el } & 13 \text { de } & \text { mayo }\end{array}$ http://www.unaids.org/sites/default/files/en/media/unaids/contentassets/documents/epidemiol ogy/2013/gr2013/20130923_FactSheet_Global_es.pdf

- Organización Internacional del Trabajo, OIT (2004). ¿Qué es el trabajo decente? Recuperado el 2 de julio del 2013, en http://www.ilo.org/americas/sala-deprensa/WCMS_LIM_653_SP/lang--es/index.htm

- Organización Internacional del Trabajo, OIT (2004). El VIH/SIDA y el mundo del trabajo: estimaciones a nivel mundial, impacto y medidas adoptadas. Página 4 - 5. Recuperado el 16 de mayo del 2013, en http://www.ilo.org/wcmsp5/groups/public/---ed_protect/---protrav/--ilo_aids/documents/publication/wcms_120484.pdf

- Organización Internacional para las Migraciones, OIM (2005). Estudio de caracterización de los factores de riesgo y vulnerabilidad de la población migrante frente al VIH/SIDA. $\begin{array}{lllllll}\text { Recuperado el } & 2 & \text { de } & \text { julio } & \text { del }\end{array}$ http://web.minsal.cl/portal/url/item/85381414c5fb11a9e04001011e015920.pdf

- Organización Mundial de la Salud, OMS (2004). Informe sobre la salud en el mundo. Capítulo I: Consecuencias humanas, sociales y económicas. Recuperado el 16 de julio del 2013, en http:/www.who.int/whr/2004/chapter1/es/index4.html 
- Undurraga, C. (2011). Psicología del adulto. De la conquista del mundo a la conquista de sí mismo. Santiago: Ediciones UC.

- Zapata, R. (2011). El Trabajo como expresión de libertad. Una aproximación al análisis marxista. Revista electrónica Forum. Recuperado el 2 de noviembre del 2013, en http://www.eafit.edu.co/revistas/forum-doctoral/Documents/edicion-4/El-trabajo-comoexpresi\%C3\%B3n-de-libertad.pdf 